\title{
PEMBUATAN PEREKAT LIGNIN RESORSINOL FORMALDEHID DARI NATRIUM LIGNOSULFONAT TANDAN KOSONG KELAPA SAWIT
}

\author{
Siti Maysarah*, Netti Herlina \\ Departemen Teknik Kimia, FakultasTeknik,Universitas Sumatera Utara, \\ Jl. Almamater Kampus USU Medan 20155, Indonesia \\ *Email : icha_b0nar@yahoo.com
}

\begin{abstract}
Abstrak
Tandan kosong kelapa sawit (TKKS) merupakan limbah dari pabrik kelapa sawit yang pemanfaatannya masih terbatas. Pemanfaatan lignin dari TKKS yang dilakukan adalah pembuatan perekat alami. Pembuatan perekat ini dilakukan dalam beberapa tahap yaitu pembuatan serbuk TKKS bebas ekstraktif, isolasi lignin, pembuatan natrium lignosulfonat, pemurnian natrium lignosulfonat dan pembuatan perekat. Pembuatan perekat lignin resorsinol formaldehid ini dilakukan dengan perbedaan perbandingan mol NaLS : resorsinol : formaldehida yaitu 1:1:1; 1:1:2; dan 1:1:3. Hasil yang didapatkan dari uji kenampakan perekat memiliki warna coklat kehitaman. $\mathrm{pH}$ dari setiap perbandingan yaitu perbandingan 1:1:1 nilainya 11,2 , perbandingan $1: 1: 2$ nilainya 11,4 dan perbandingan 1:1:3 nilainya 12,0 . Berat jenis perekat perbandingan $1: 1: 1$ yaitu 1,2857 , perbandingan 1:1:2 1,2119, dan perbandingan 1:1:3 nilai berat jenisnya 1,3097. Viskositas dari perbandingan 1:1:1 nilainya $108,83 \mathrm{cps}$, perbandingan $1: 1: 2$ nilainya $94,31 \mathrm{cPs}$ dan perbandingan $1: 1: 3$ nilainya 129,92 cPs. Sisa penguapan pada perbandingan 1:1:1 sebesar 50,77\%, perbandingan 1:1:2 sebesar 42,35\% dan perbandingan 1:1:3 sebesar $41,01 \%$. Hasil yang didapat dibandingkan dengan standar fenol formaldehida yaitu SNI 06-4567-1998 fenol formaldehid cair dan dihasilkan bahwa perbandingan 1:1:3 merupakan perbandingan yang terbaik dibanding dengan perbandingan lainnya.
\end{abstract}

Kata kunci : tandan kosong kelapa sawit, perekat lignin resorsinol formaldehid, natrium lignosulfonat, resorsinol, formaldehid

\begin{abstract}
Oil palm empty fruit bunchesn are waste from palm oil mill utilization is still limited. Lignin utilization of oil palm empty fruit bunhes made of natural adhesive manufacture. Making adhesive is carried out in several stages namely the manufacture of powder oil palm empty fruit bunches free extractives, lignin isolation, the manufacture of sodium lignosulfonate, sodium purification lignosulfonate and the manufacture of adhesive. Making the lignin resorcinol formaldehide adhesive is done by differences sodium lignosulfonate : resorcinol : formaldehyde mole ratio are ratio 1:1:1, ratio 1:1:2 and ratio 1:1:3. The results obtained from testing the appearance of the adhesive has a blackish brown color. pH of each ratio is ratio 1:1:1 11,2, ratio 1:1:2 11,4 and ratio 1:1:3 12,0. Adhesive densities are ration 1:1:1 1,2857, ratio 1:1:2 1,2119, and ratio 1:1:3 1,3097. Viscosities are ratio 1:1:1 108,83 cps, ratio 1:1:2 94,31 cps and ratio 1:1:3 129,92 cps. The rest of the evaporation are ratio $1: 1: 1 \quad 50,77 \%$, ratio $1: 1: 2 \quad 42,35 \%$ and ratio $1: 1: 341,01 \%$. Test results compared with standard phenol formaldehyde which is SNI 06-4567-1998 liquid phenol formaldehyde and result ratio 1:1:3 the best of another ratio .
\end{abstract}

Keywords : oil palm empty fruit bunches, adhesive lignin recolcinol formaldehyde, sodium lignosulfonate, recolcinol, formaldehyde

\section{Pendahuluan}

Tandan kosong kelapa sawit (TKKS) merupakan limbah dari pabrik kelapa sawit yang pemanfaatnya masih terbatas sebagai pupuk organik yang memiliki nilai tambah yang rendah. Pada tahun 2010 produksi buah sawit mencapai 21.958.120 ton dan pada tahun 2011 produksi tersebut mencapai 22.508.011 ton. Setiap produksi kelapa sawit menghasilkan limbah berupa tandan kosong sawit $23 \%$, cangkang $8 \%$, serat $12 \%$, dan limbah cair $66 \%$. Limbah TKKS pada tahun 2010 mencapai 5.050.367,6 ton dan pada tahun 2011 mencapai 5.176.842,53 ton. Dengan jumlah limbah tandan kosong yang terus meningkat, jika tidak dimanfaatkan secara optimal maka dapat berakibat buruk bagi lingkungan [9].
Pemanfaatan limbah kelapa sawit yang umum dilakukan saat ini diantaranya adalah penggunaan TKKS sebagai mulsa di kebun, akan tetapi biaya transportasi yang dikeluarkan per unit nutrisi cukup tinggi dan dapat menimbulkan ledakan populasi hama kumbang yang mematikan tanaman kelapa sawit. Pemanfaatan lain dari TKKS adalah penggunaannya dalam pembuatan pupuk organik. TKKS dalam pemanfaatannya dapat dibakar dengan incenerator sehingga abunya dapat digunakan sebagai pupuk kalium. Namun usaha pembakaran TKKS tersebut ternyata tidak efektif dan dilarang oleh pemerintah karena dapat menimbulkan pencemaran udara [4].

Perekat sintetik merupakan perekat yang berbahan baku hasil olahan minyak bumi. Kelemahan perekat sintetis adalah ketersediaan 
sumber bahan baku perekat yang semakin berkurang dan timbulnya emisi formaldehida dari produk material hasil perekatan terhadap lingkungan. Perekat berbahan formaldehida itu sendiri diperoleh sebagai hasil olahan minyak bumi yang tidak dapat pulih. Sementara itu minyak bumi merupakan sumber daya alam yang tidak dapat diperbaharui dan persediaannya sewaktu-waktu akan habis. Maka perlu adanya bahan pengganti dalam pembuatan perekat.

Penelitian dan pengembangan mengenai perekat terus dilakukan untuk mengeksplorasi perekat alami baru yang kualitasnya tinggi dan dampak negatif terhadap lingkungan yang rendah [8].

\section{Teori}

Lignin adalah senyawa organik polimer yang banyak dan penting dalam dunia tumbuhan selain selulosa. Struktur lignin sangat beraneka ragam tergantung dari jenis tanamannya. Lignin merupakan komponen terbesar yang terdapat dalam larutan lindi hitam. Secara umum polimer lignin disusun oleh unit-unit fenil propana yaitu $p$-kumaril alkohol, koniferil alkohol, dan sinapil alkohol.

Natrium lignosulfonat (NaLS) dapat disintesis dari lignin dengan reaksi sulfonasi. Reaksi sulfonasi merupakan reaksi yang melibatkan pemasukan gugus sulfonat ke dalam lignin. Proses sulfonasi pada lignin bertujuan untuk mengubah sifat hidrofilitas dari lignin yang tidak larut dalam air dengan memasukkan gugus sulfonat yang lebih polar dari gugus hidroksil, sehingga akan meningkatkan sifat hidrofilitasnya dan menjadikan lignosulfonat [3].

Tabel 1. Persyaratan Mutu Fenol Formaldehida Cair untuk Perekat Kayu Lapis [8]

\begin{tabular}{|c|l|c|}
\hline No & \multicolumn{1}{|c|}{ Pengujian } & $\begin{array}{c}\text { Berdasarkan SNI 06 } \\
-4567-1998\end{array}$ \\
\hline 1. & Bentuk & Cair \\
\hline 2. & Kenampakan & $\begin{array}{c}\text { Merah Kehitaman } \\
\text { dan bebas dari } \\
\text { kotoran }\end{array}$ \\
\hline 3. & pH $\left(25^{\circ} \mathrm{C}\right)$ & $10,0-13,0$ \\
\hline 4. & $\begin{array}{l}\text { Kekentalan (25 } \\
\left.{ }^{0} \mathrm{C}\right)\end{array}$ & $130-300$ \\
\hline 5. & $\begin{array}{l}\text { Berat Jenis (25 } \\
\left.{ }^{0} \mathrm{C}\right)\end{array}$ & $1,165-1,200$ \\
\hline 6. & Sisa penguapan & $7-45 \%$ \\
\hline 7. & $\begin{array}{l}\text { Massa glatinasi } \\
\left(100{ }^{0} \mathrm{C}\right)\end{array}$ & $>30$ Menit \\
\hline
\end{tabular}

Perekat (adhesives) adalah suatu yang memiliki kemampuan untuk mempersatukan bahan sejenis atau tidak sejenis melalui ikatan permukaan. Dilihat dari reaksi perekat terhadap panas, maka perekat dapat dibedakan atas perekat termoset dan termoplastis. Perekat termoset merupakan perekat yang dapat mengeras bila terkena panas dan reaksinya bersifat tidak dapat balik. Perkat jenis ini jika sudah mengeras, tidak dapat lagi menjadi lunak. Contoh perekat yang termasuk jenis ini adalah fenol formaldehida, urea formaldehida, melamin formaldehida, isosianat dan resorsinol formaldehida. Perekat termoplastis adalah perekat yang dapat melunak jika terkana panas dan menjadi mengeras jika suhunya telah turun. Contoh perekat yang termasuk jenis ini adalah polyvinil adhesive, ceellulose adhesive [2].

\section{Metodologi}

Bahan baku yang digunakan adalah TKKS, resorsinol dan formaldehid. TKKS yang didapat dihassilkan dari limbah pabrik kelapa sawit, resorsinol didapatkan dari CV. Rudang Jaya, dan formaldehid didapatkan dari Laboraturium Proses Industri Kimia Departemen Teknik Kimia Fakultas Teknik Universitas Sumatera Utara.

Prosedur kerja dari penelitian ini terdiri dari 6 tahap, yaitu pembuatan serbuk TKKS bebas ekstraktif, isolasi lignin, pembuatan natrium lognosulfonat, pemurnian natrium lignosulfonat, pembuatan perekat Lignin resorsinol Formaldehid (LRF), dan penentuan analisa perekat LRF.

\section{Pembuatan Serbuk TKKS Bebas Ekstraktif}

Pembuatan serbuk TKKS bebas ekstraktif dilakukan dengan cara TKKS digiling, diayak untuk mengambil serbuknya yang lolos ayakan 50 mesh sebagai bahan baku. TKKS yang telah melewati ayakan dikeringkan dioven pada suhu 60 ${ }^{0} \mathrm{C}$ selama 16 jam. TKKS kering diekstraksi dengan menggunakan heksana : etanol $96 \%$ (2:1, v/v) selama 6 jam pada soxlet apparatus. Dikeringkan dalam oven pada suhu $60{ }^{\circ} \mathrm{C}$ selama 16 jam. Diekstraksi dengan etanol $96 \%$ selama 4 jam. Diekstraksi dengan air mendidih selama 2 jam.

\section{Isolasi Lignin}

Isolasi lignin dilakukan pada serbuk TKKS bebas pengotor, 300 gr ditimbang dan dimasukkan kedalam digester dengan penambahan larutan pemasak 10:1 v/b, dimana komposisi larutan pemasak adalah etanol $96 \%$ : air (1:1). Pada digester ditambahkan katalis natrium Hidroksida $(\mathrm{NaOH}) 10 \%$. Campuran kemudian dimasak pada digester hingga mencapai suhu 170 ${ }^{\circ} \mathrm{C}$ kemudian dipertahankan selama 1 jam pada suhu tersebut. Lindi hitam (lignin terlarut) kemudian disaring dengan kain. Lindi hitam kemudian ditambahkan asam sulfat $15 \%$ sampai $\mathrm{pH} 2$, kemudian didiamkan selama 8 jam. Kemudian disaring dengan kertas saring. Endapan hasil saringan dimasukkan dalam beaker glass. Endapan dilarutkan dengan Natrium Hidroksida $(\mathrm{NaOH}) 1 \mathrm{~N} 100 \mathrm{ml}$. Kemudian disaring dengan kertas saring. Endapan dicuci dengan asam sulfat $\left(\mathrm{H}_{2} \mathrm{SO}_{4}\right) 10 \%$, v/v. Endapan disaring dengan kertas saring. Endapan kemudian dicuci dengan aquades. 
Endapan kemudian disaring dengan kertas saring. Endapan kemudian dikeringkan dalam oven pada suhu $60{ }^{\circ} \mathrm{C}$ selama 16 jam.

\section{Pembuatan Natrium Lignosulfonat}

Hasil dari isolasi lignin ditimbang sebanyak 5 gr, dicampurkan dengan $\mathrm{NaHSO}_{3}$ dengan perbandingan mol lignin : $\mathrm{NaHSO}_{3}$ adalah 1:0,5 lalu dimasukkan dalam $150 \mathrm{ml}$ air. Lignin dimasukkan dalam labu leher tiga ukuran $500 \mathrm{ml}$ menggunakan pengaduk. Kemudian $\mathrm{pH}$ diatur 7 dengan cara penambahan $\mathrm{NaOH} 15 \%$ yang ditunjukkan pada skala indikator $\mathrm{pH}$ universal. Campuran tersebut diaduk pengaduk agar campuran bereaksi sempurna. Campuran selanjutnya direfluks pada suhu $106{ }^{0} \mathrm{C}$ sambil dilakukan pengadukan dengan alat pengaduk agar campuran reaksi sempurna, pemanas listrik selama 4 jam.

\section{Pemurnian Natrium Lignosulfonat}

Untuk memurnikan Natrium

Lignosulfonat, hasil refluks pada pembuatan natrium lignosulfonat didestilasi pada suhu $100{ }^{\circ} \mathrm{C}$ untuk menguapkan air, guna mengurangi volume. Larutan yang telah pekat dimasukkan ke dalam corong pemisah, untuk memisahkan sisa lignin. Filtratnya berupa natrium lignosulfonat yang masih mengandung $\mathrm{NaHSO}_{3}$ (sisa reaksi). Filtrat kemudian ditambahkan methanol sambil dikocok kuat sehingga $\mathrm{NaHSO}_{3}$ terendapkan dan dimasukkan dalam corong pemisah. Metanol yang terdapat dalam filtrat diuapkan. NaLS pekat yang diperoleh dikeringkan dalam oven pada suhu 60 ${ }^{\circ} \mathrm{C}$.

\section{Pembuatan Perekat Lignin Resorsinol Formaldehida \\ Untuk membuat perekat LRF, sebanyak} 20 gram NaLS ditimbang kemudian dicampur dengan $\mathrm{NaOH} 10 \%$ dalam gelas piala. Diaduk pada suhu ruangan. Ditambahkan larutan $\mathrm{NaOH} 50 \%$ sambil diaduk dan $\mathrm{pH}$ mencapai 10 . Larutan yang terbentuk kemudian ditambahkan dengan resorsinol sedikit demi sedikit dan diaduk sampai homogen. Larutan dikondisikan sampai $\mathrm{pH}$ mencapai 11 dengan menambahkan larutan $\mathrm{NaOH} \quad 50 \%$. Ditambahkan larutan formaldehida $37 \%$ sambil diaduk. Larutan $\mathrm{NaOH} 10 \%$ dimasukkan, dan campuran diaduk lagi sampai $\mathrm{pH}$ larutan mencapai pH 11. Reaksi dilakukan pada suhu kamar

\section{Analisa Perekat LRF}

perekat yang dihasilkan akan dianalisa sifat fisik perekat tersebut meliputi kenampakan perekat, $\mathrm{pH} /$ keasaman, berat jenis, dan kekentalan (viskositas) perekat LRF pada suhu kamar serta kadar sisa penguapan pada $105{ }^{\circ} \mathrm{C}$.

\section{Hasil dan Pembahasan Uji Kenampakan}

Tabel 2. Hasil Uji kenampakan Perekat LRF

\begin{tabular}{|c|l|c|}
\hline Perbandingan & \multicolumn{1}{|c|}{ Kenampakan } & $\begin{array}{c}\text { SNI 06- } \\
4567- \\
1998\end{array}$ \\
\hline $1: 1: 1$ & $\begin{array}{l}\text { Cairan, warna } \\
\text { coklat kehitaman } \\
\text { dan bebas } \\
\text { pengotor }\end{array}$ & \\
\hline $1: 1: 2$ & $\begin{array}{l}\text { Cairan, warna } \\
\text { coklat kehitaman } \\
\text { dan bebas } \\
\text { pengotor bairan, } \\
\text { merah } \\
\text { kehitaman } \\
\text { dan bebas } \\
\text { pengotor }\end{array}$ \\
\hline $1: 1: 3$ & $\begin{array}{l}\text { Cairan, warna } \\
\text { coklat kehitaman } \\
\text { dan bebas } \\
\text { pengotor }\end{array}$ \\
\hline
\end{tabular}

Dari tabel 2. hasil uji kenampakan perekat LRF yang didapat berbentuk cairan dan memiliki coklat kehitaman serta bebas dari pengotor. Sedangkan pada standar mutu perekat fenol formaldehida pada SNI 06-4567-1998, bentuk perekat adalah cairan dan kenampakannya merah kehitaman dan bebas dari pengotor. Warna perekat LRF yang didapat berbeda dengan SNI fenol formaldehida hal ini dikarenakan perbedaan dari lignin yang dihasilkan.

Menurut Pizzi dalam Harisyah Manurung (2009), warna yang dihasilkan diduga berasal dari perpaduan lignin isolat dengan resorsinol, yang merupakan senyawa fenolik mengandung 1 gugus hidroksi tambahan pada inti aromatik membentuk posisi meta [5].

\section{Uji pH (Derajat Keasaman)}

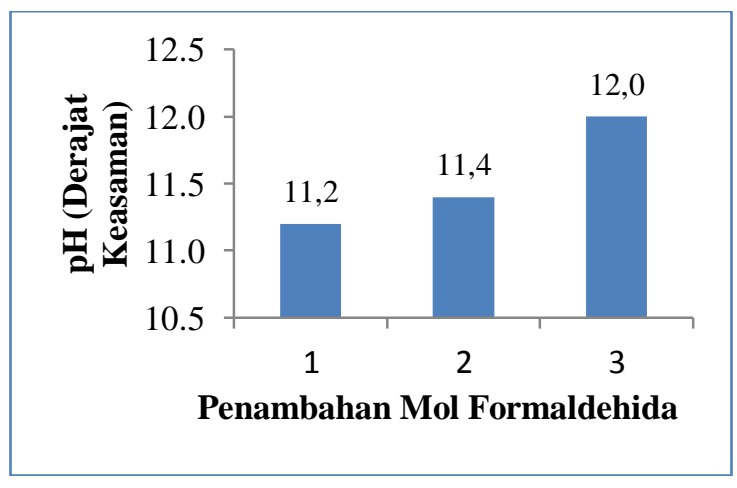

Gambar 1. Pengaruh Penambahan Mol Formaldehida Terhadap Nilai pH/Keasaman Perekat LRF

Berdasarkan gambar 1. nilai $\mathrm{pH}$ rata-rata dari setiap perbandingan yaitu perbandingan 1:1:1 nilainya 11,2 , perbandingan $1: 1: 2$ nilainya 11,4 dan perbandingan $1: 1: 3$ nilainya 12,0 . Nilai $\mathrm{pH}$ ini tidak 
berpengaruh pada perbandingan jumlah formaldehida pada pembuatan perekat LRF. Ini juga dapat diketahui dari perlakukan yang dilakukan bahwa $\mathrm{pH}$ akhir dari pembuatan perekat LRF adalah pada $\mathrm{pH}$ 11. Berdasarkan data ini nilai $\mathrm{pH}$ perekat LRF yang dihasilkan sesuai dengan SNI 06-4567-1998 yang mensyaratkan nilai $\mathrm{pH}$ sebesar 10,0-13,0.

Dan Menurut Medynda, sifat basa yang terdapat pada perekat ini sebabkan karena adanya penambahan $\mathrm{NaOH} 50 \%$ ke dalam larutan perekat. Sifat basa diperlukan untuk kesesuaian perekat dan kayu dan agar tidak merusak struktur kayu yang direkat [6].

Menurut Adi Santoso (2003), pH resin merupakan targer akhir reaksi kondensasi yang disengaja dikondisikan basa, namun diupayakan tanpa menimbulkan pengaruh negatif terhadap kayu (pH 8-11) dengan tujuan memperlambat reaksi polimerisasi sehingga resin cair stabil dalam waktu relatir lama selama penyimpanan [1].

\section{Berat Jenis}

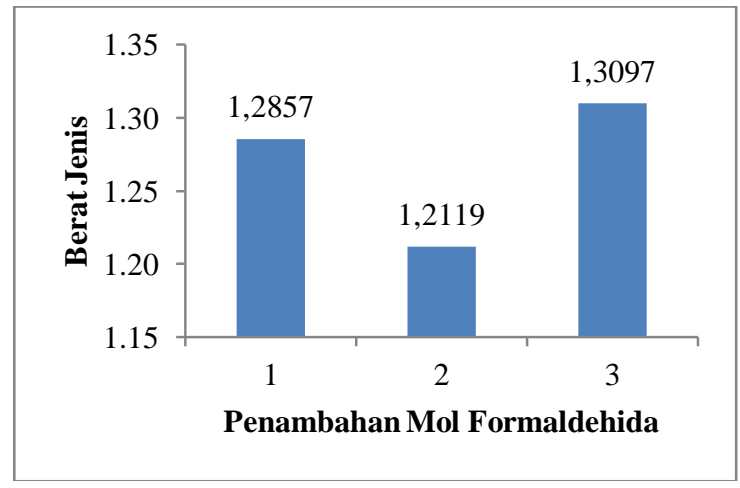

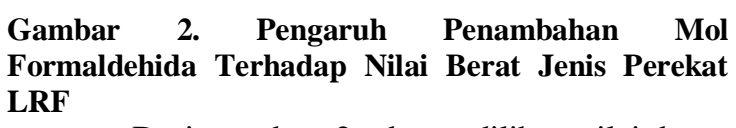

Dari gambar 2. dapat dilihat nilai berat jenis dari perekat LRf pada Perbandingan 1:1:1 adalah 1,2857, pada perbandingan 1:1:2 1,2119 dan pada perbandingan 1:1:3 sebesar 1,3097. Hai ini menunjukkan adanya pengaruh dari penambahan mol formaldehida pada perekat yang dihasilkan.

Berdasarrkan data di atas nilai berat jenis untuk setiap perbandingan lebih besar dari standar yang diacu. Pada SNI 06-4567-1998 mensyaratkan nilai berat jenis sebesar 1,165 - 1,200. Maka nilai berat jenis perekat LRF yang dihasilkan tidak memenuhi standar. Namun nilai ini masih mendekati dari standar tersebut.

Berat jenis perekat dipengaruhi oleh komponen-komponen penyusun perekat tersebut, sesuai dengan Setiawan dalam Medynda ddk (2012), berat jenis perekat menunjukkan berat jenis masing-masing komponen penyusun perekat tersebut, semakin banyak komponen perekat yang berat jenisnya tinggi maka berat jenis perekat ini juga akan semakin tinggi [6].

\section{Viskositas}

Dari gambar 3. dapat dilihat bahwa nilai viskositas dari perekat LRF pada perbandingan $1: 1: 1$, perbandingan $1: 1: 2$ dan perbandingan $1: 1: 3$ adalah 108,83 cps, 94,31 cps dan 134,63 cps. Dari hasil pengujian nilai viskositas dari perekat yang dihasilkan maka penambahan mol formaldehida mempengaruhi nilai viskositas perekat LRF.

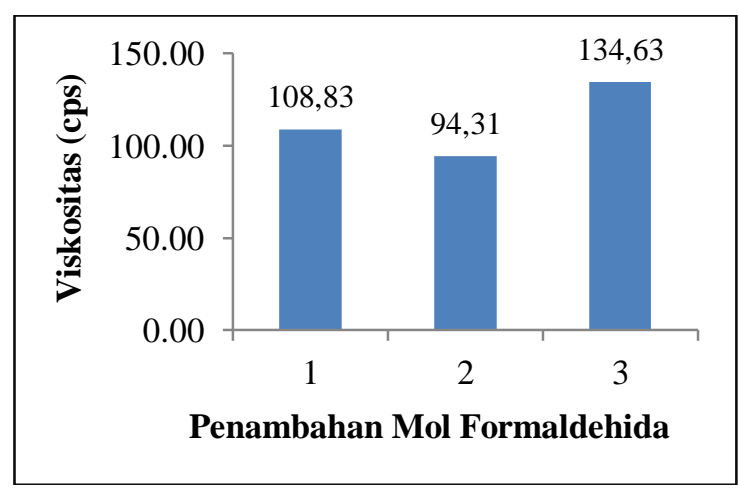

Gambar 3. Pengaruh Penambahan Mol Formaldehida Terhadap Viskositas Perekat LRF

Pada SNI 06-4567-1998 nilai viskositas perkat sebesar 130-300 cps. Hasil yang didapatkan nilai viskositas 1:1:3 telah sesuai dengan standar, namun untuk perbandingan 1:1:1 dan perbandingan 1:1:2 nilainya lebih kecil dari standar sehingga belum sesuai dengan standar SNI 06-4567-1998.

Menurut Ruhendi dalam Medynda dkk (2012), semakin kecil viskositas perekat, maka semakin besar kemampuan perekat untuk mengalir, berpindah, dan mengadakan penetrasi dan pembasahan. Dengan demikian maka kualitas perekatan akan meningkat sampai pada batas keenceran tertentu, karena perekat yang terlalu encer justru akan menurunkan nilai keteguhan rekat. Sebaliknya, semakin tinggi kekentalan, maka kemampuan untuk membasahi dan berpenetrasi ke dalam permukaan yang direkat akan semakin sulit [6].

\section{Sisa Penguapan}

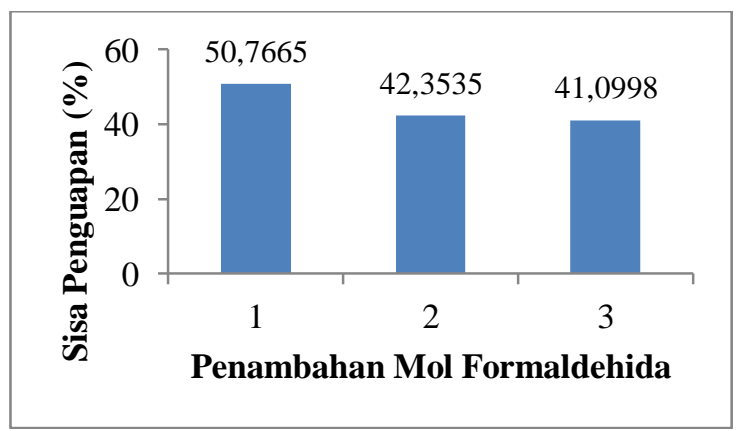

Gambar 4. Pengaruh Penambahan Mol Formaldehida Terhadap Nilai Sisa Penguapan Perekat LRF 
Berdasarkan gambar 4. dapat dilihat nilai sisa penguapan perekat LRF. Pada perbandingan 1:1:1, perbandingan $1: 1: 2$ dan perbandingan $1: 1: 3$ adalah $50,7665 \%, 42,3535 \%$ dan $41,0998 \%$. Ini menunjukkan nilai berat jenis perekat LRF yang dihasil dipengaruhi oleh penambahan mol formaldehida. Berdasarkan data ini nilai sisa penguapan pada perbandingan 1:1:1 tidak sesuai dengan standar, sedangkan untuk perbandingan 1:1:2 dan perbandingan 1:1:3 telah sesuai dengan standar. Standar perekat dari SNI 06-4567-1998 besarnya nilai sisa penguapan adalah sebesar 40$45 \%$.

Dari data yang diperoleh, perbandingan formaldehida dalam pembuatan perekat menunjukkan dengan adanya penambahan formaldehida maka semakin berkurang sisa penguapan. Menurut Harisyah (2009) meningkatnya resin padatan menambah sempurnanya reaksi kopolimerisasi, sehingga molekul-molekul yang terkandung didalamnya semakin meningkat. Maka diharapkan semakin banyak molekul-molekul perekat yang akan bereaksi dengan kayu sehingga meningkatkan daya rekat menjadi lebih baik [5].

\section{Karakteristik Senyawa Penyusun Perekat Lignin Resorsinol Formaldehid (LRF)}

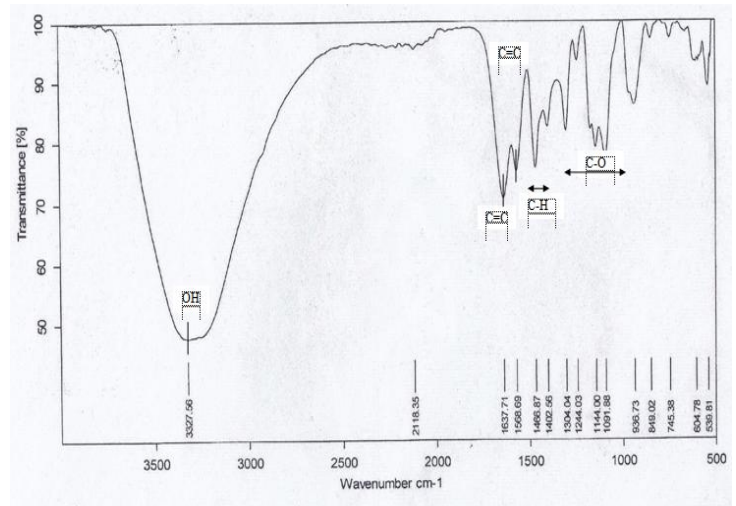

Gambar 5. Grafik FT-IR Perekat LRF

Tabel 3. Pencirian Gugus-Gugus Fungsi Perekat LRF [7]

\begin{tabular}{|c|c|l|}
\hline $\begin{array}{c}\text { Frekuensi } \\
\left(\mathrm{cm}^{-1}\right) \text { pada } \\
\text { penelitian }\end{array}$ & $\begin{array}{c}\text { Standar } \\
\text { kisaran pita } \\
\text { serapan }\left(\mathrm{cm}^{-1}\right)\end{array}$ & $\begin{array}{c}\text { Keterangan } \\
\text { gugus Fungsi }\end{array}$ \\
\hline 3.327 & $3.385-3.443$ & OH fenolik \\
\hline 1.637 & $1.680-1.600$ & $\mathrm{C}=\mathrm{C}$ alkena \\
\hline 1.568 & $1.600-1475$ & $\mathrm{C}=\mathrm{C}$ aromatik \\
\hline 1.466 & $1.465-1.370$ & $\mathrm{C}=\mathrm{H}$ metilena \\
\hline 1.402 & $1.465-1.370$ & $\mathrm{C}=\mathrm{H}$ metilena \\
\hline $1.304-1.091$ & $1.300-1000$ & $\mathrm{C}-\mathrm{O}$ dari eter \\
\hline $1.244-1.091$ & $1.260-1000$ & Senyawa fenolik \\
\hline
\end{tabular}

Dari gambar 5. dan table 3. dapat dilihat bahwa frekuensi $3.327 \mathrm{~cm}^{-1}$ mengindikasikan adanya gugus $\mathrm{OH}$. Untuk mengindifikasikan ikatan
$\mathrm{C}=\mathrm{C}$ pada alkena muncul frekuensi 1.680-1.600 $\mathrm{cm}^{-1}$, untuk cincin aromatik 1.600-1.475 $\mathrm{cm}^{-1}$ [7]. Pada gambar 6. muncul frekuensi $1.466 \mathrm{~cm}^{-1}$ yang menunjukkan adanya ikatan $\mathrm{C}=\mathrm{C}$. Hal ini sesuai dengan Bhunia et al. (1998) dalam Risfaheri et al. (2005) yang menyatakan pita absorpsi $\mathrm{C}=\mathrm{C}$ muncul pada frekuensi $1.625-1.430 \mathrm{~cm}^{-1}$.

Menurut Risfaheri et al. (2005) [24] gugus $\mathrm{C}-\mathrm{H}$ muncul pada frekuensi $1.465-1.370 \mathrm{~cm}^{-1}$, dari gambar di atas dapat lihat frekuensi 1.402-1.466 $\mathrm{cm}^{-1}$ menunjukkan adanya gugus $\mathrm{C}-\mathrm{H}$ dari metilena. Frekuensi pada 1.091 menunjukkan adanya gugus C-O dari eter dan senyawa fenolik pada frekuensi $1.144-936 \mathrm{~cm}^{-1}$. Berdasarkan Risfaheri et al. (2005) [7] frekuensi $1.300-1.000 \mathrm{~cm}^{-1}$ menandai adanya gugus C-O dari eter dan senyawa fenolik (1.260$1.000 \mathrm{~cm}^{-1}$ ).

Berdasarkan pada grafik pengukuran FTIR pada perekat LRF dapat dilihat gugus-gugus pada perekat LRF memiliki kesamaan dengan gugus-gugus pada perekat Fenol Formaldehida. Gugus-gugus penyusunnya yaitu gugus $\mathrm{O}-\mathrm{H}, \mathrm{C}=\mathrm{C}$ aromatik, C-H metilena, $\mathrm{C}-\mathrm{O}$ dan gugus senyawa fenolik.

\section{Kesimpulan dan Saran}

Pemanfaatan TKKS sebagai perekat memiliki potensi yang besar karena TKKS memiliki kandungan lignin yang besar yaitu sebesar $16 \%$. Hasil dari uji perekat lignin resorsinol formadehid pada perbandingan 1:1:1 adalah perekat berbentuk cairan berwarna coklat kehitaman dan bebas pengotor, $\mathrm{pH} 11,2$, berat jenis 1,2857 , viskositas 108,83 cps dan sisa penguapan $50,77 \%$. Hasil dari uji perekat lignin resorsinol formadehid pada perbandingan 1:1:2 adalah perekat berbentuk cairan berwarna coklat kehitaman dan bebas pengotor, $\mathrm{pH} 11,4$, berat jenis 1,219, viskositas 94,31 cps dan sisa penguapan $42,35 \%$. Hasil dari uji perekat lignin resorsinol formadehid pada perbandingan 1:1:3 adalah perekat berbentuk cairan berwarna coklat kehitaman dan bebas pengotor, $\mathrm{pH} 12,0$, berat jenis 1,3097 , viskositas 134,63 cps dan sisa penguapan $41,01 \%$. Perekat pada perbandingan 1:1:3 lebih memenuhi standar perekat SNI 06-4567-1997 dibanding pada perbandingan lainnya. Penambahan mol formaldehida dalam pembuatan perekat lignin resorsinol formaldehid memiliki pengaruh yang besar.

Saran untuk kedepannya adalah Penelitian tentang pembuatan perekat LRF ini sebaiknya dilakukan pengujian lanjutan pada kayu sehingga dapat ditentukan aplikasi dari perekat yang dihasilkan. Pengujian waktu glatinasi perekat LRF juga perlua dilakukan untuk perekat LRF untuk mengetahui waktu perekatan dari perekat yang dihasilkan. 


\section{Daftar Pustaka}

[1] Adi Santoso, Komposisi Resin dan Kadar Adiktif dalam Perekat Lignin Resorsinol Formaldehida pada Kayu Lamina Kempas, Jurnal Teknologi Hasil Hutan, Institut Pertanian Bogor, Vol. 16 No. 2, Bogor, 2003.

[2] Firda Aulya Syamani, Peningkatan Kualitas Papan Komposit Sisaal (Agave Sisalana Perr.) Dengan Perlakuan Mekanis, Tesis, Sekolah Pasca Sarjana, Institut Pertanian Bogor, Bogor, 2009.

[3] Gustini Syabirin, Abdul Aziz Darwis, Ani Suryani,Wasrin Syafii, Pengaruh Nisbah Pereaksi (Lignin Eupcalyptus - Natrium Bisulfit) Dan pH Awal Reaksi Sulfonasi Terhadap Karakteristik Natrium Lignosulfonat, Jurnal Teknologi Industri Pertanian, 19(2), 101-106, Bogor, 2010.

[4] Heradewi, Isolasi Lignin dari Lindi Hitam Proses Pemasakan Organosolv Serat Tandan Kosong Kelapa Sawit (TKKS), Skripsi Institut Pertanian Bogor, Bogor, 2007.

[5] Harisyah Manurung, Pemanfaatan Lignin dari Lindi Hitam Sebagai Bahan Baku Perekat Lignin Resorsinol Formaldehida (LRF), Skripsi Universitas Sumatera Utara, Medan, 2009.

[6] Marcelila Medynda, Pengembangan Perekat Likuida Dari Limbah Kulit Buah Kakao (Theobroma Cacao L.), Skripsi, Program Sarjana Fakultas Kehutanan USU, Medan, 2012.

[7] Risfaheri, et al., Optimasi Komposisi Kardanol dari Minyak Kulit Mete Sebagai Subtitusi Fenol Dalam Formulasi Perekat Fenol Formaldehida, Jurnal Pascapanen 2(1) 2005: 24-33.

[8] Tito Sucipto, Karakterisasi Partikel Dan Likuida Tandan Kosong Sawit, Tesis, Sekolah Pascasarjana IPB, Bogor, 2009.

[9] Yuliani, Kualitas Papan Partikel Tandan Kosong Kelapa Sawit (Elaeis guineensis Jacq) Menggunakan Perekat Likuida dengan penambahan Resorsinol, Skripsi Institut Pertanian Bogor, Bogor, 2012. 